\title{
Erratum to "Impact of Media Violence on Aggressive Attitude for Adolescents" [Health 5 (2013) 2156-2161]
}

\author{
Qian Zhang1*, Dingyong Xiong², Jingjin Tian' ${ }^{1}$ \\ ${ }^{1}$ School of Applied Technology, Southwest University, Chongqing, China \\ ${ }^{2}$ Sichuan Vocational College of Industrial Management, Mianzhu, China \\ Email: zhq@swu.edu.cn
}

Received: October 27, 2013

Accepted: November 23, 2013

Published: December 12, 2013

Copyright (C) 2019 by author(s) and Scientific Research Publishing Inc. This work is licensed under the Creative Commons Attribution International License (CC BY 4.0).

http://creativecommons.org/licenses/by/4.0/ Open Access
The original online version of this article (Zhang, Q., Xiong, D.Y. and Tian, J.J. (2013) Impact of Media Violence on Aggressive Attitude for Adolescents. Health, 5, 2156-2161. http://dx.doi.org/10.4236/health.2013.512294) was published as some results data reported mistakenly. The author wishes to correct the errors to:

\section{Abstract}

The goal of this study was mainly to examine the impact of media violence on aggressive attitude among Chinese adolescents by using a modified STROOP task. 74 adolescents participated in this study, 37 were assigned to violent movie group and 37 were assigned to non-violent movie group. The results showed no main effect of violent movie on aggressive attitude, but a significant interaction between Movie Type and Gende, and boys showed a significantly higher aggressive attitude than girls after watching violent movies. This implied that violent movies could not effectively affect aggressive attitude for all adolescents but just for boys in China.

\subsection{Participants}

74 participants (boys $=37$, girls $=37$ ) recruited from a high school in southwestern part of China participated in the study. Participants ranged in age from 15 to 19 years $(M=16.55, S D=1.61)$.

\subsection{Experimental Design}

Multi-factor experimental design was used, with movie type, gender and trait aggressiveness as independent variables and aggressive attitude as dependent va- 
riable. 2 (movie type: violent vs. non-violent) $\times 3$ (trait aggressiveness: HA, MA, LA) $\times 2$ (gender: boy vs. girl) repeated four measures analysis of variance (ANOVA) was conducted with movie type, trait aggressiveness, and gender as between-group factor, and goal word as within-group factor. According to related study [18], the score of participants at the top one third of BPAQ was defined as HA, the last one third of BPAQ was seen as LA, and the rest were thought as MA in terms of score distribution.

\section{Results}

In the study, we hypothesized the RT of aggressive words was longer than that of nonaggressive words (compared to participants watching non-violent movie clips). Thus, we postulated each participant had an aggressively activated score (AAS), which meant the mean RT values of aggressive words subtracted nonaggressive words and divided by 2 , representing the aggressive attitude among adolescents among each group in the study.

Multi-factor analysis of variance (ANOVA) was carried out to examine whether there significant difference in AAS among independent variables. The results can be seen in Table 1 .

\section{Multi-factor ANOVA for movie type, gender and trait aggressiveness in AAS}

\begin{tabular}{ccc} 
Independent Variables & Mean Square & $\mathrm{F}$ \\
Movie Type & 7551.07 & 1.96 \\
Movie Type $\times$ Gender & $18,337.83$ & $4.76^{*}$ \\
Movie Type $\times$ Trait Aggressiveness & 3181.84 & 0.83 \\
\hline
\end{tabular}

Note: AAS = aggressively activated score (mean RT values of aggressive words minus nonaggressive words $/ 2) ;{ }^{*} p<0.05 ;{ }^{* *} p<0.01 ;{ }^{* *} p<0.001$.

Table 1 showed no significant difference in main effect of movie type on aggressive attitude $(F(1,63)=1.96, p>0.05)$. There was significant Movie Type $\times$ Gender interaction $(F(1,63)=4.76, p<0.05)$. Further simple effect analysis showed that the AAS of boys watching violent movie clip was significant higher than that of boys watching non-violent movies $(F(1,63)=6.07, p<0.05)$. The results could be seen in Table 2. Table 1 revealed no significant Movie Type $\times$ Trait Aggressiveness interaction $(F(2,63)=0.83, p>0.05)$ in AAS differences.

Table 2. Gender differences in AAS after watching movie clips.

\begin{tabular}{cccc} 
Gender & Violent Movie & Clip Non-violent Movie & Clip F \\
Boys & $184.78(15.23)$ & $124.10(19.36)$ & $6.07^{\star}$ \\
Girls & $90.08(16.77)$ & $86.69(14.28)$ & 0.02 \\
\hline
\end{tabular}

Note: AAS = aggressively activated score (mean RT values of aggressive words minus nonaggressive words $/ 2) ;{ }^{*} p<0.05 ;{ }^{* *} p<0.01 ;{ }^{* *} p<0.001$.

\section{Discussion}

The main purpose of this study was to explore the impact of media violence on 
aggressive attitude of Chinese adolescents. STREET FIGHTER and AIR CRISIS were selected as media violence and media non-violence, respectively. Our study showed that no significant difference in main effect of movie type on adolescents' aggressive attitude and no significant Movie Type $\times$ Trait Aggressiveness interaction. However, a significant Movie Type $\times$ Gender interaction was found, and that aggressive attitude was significantly primed by violent movies only for boys, but not for girls. Specifically, boys yielded significant stronger aggressive attitude than did girls. Thus, we inferred that boys were more likely to watch violent movies than girls, thus leading to rapid development of their aggressively cognitive framework.

In consistent with our hypotheses, the study demonstrated that violent movies effectively activated the aggressive attitude of boys, which partly supporting General Aggressive Model (GAM) [19] and Cognitive Neoassociation Model (CNM) [20], which assumed that media violence could activate individual's aggressive cognition, affect, physiological arousal, and aggressive behavior. This finding supported hypothesis 2 but did not support hypothesis 1 , and replicated previous researches [21] [22] [23] [24] [25]. Moreover, aggressive attitude of HA relative to $\mathrm{BA}$ and LA adolescents was affected by violent movies at significan level, which was not in parallel with previous studies [26] [27] [28] [29]. What's more, some differences existed between the present study and previous research. For instance, previous studies showed viewers' aggression was primed by violent movies, and the main effect of movie type was significant [30]. The study, rather demonstrated no significant main effect of movie type, and that no significant difference was found in aggressive attitude between violent movie group and non-violent movie group.

\section{Conclusions}

1) Watching violent movies did not significantly increase aggressive attitude;

2) Boys had a significantly stronger aggressive attitude than girls after watching violent movies. 